\title{
Revisión
}

\section{El potencial de la maricultura de laminarias como fuente para la obtención de biocombustibles y otros bioproductos en la costa atlántica de España}

\author{
César Peteiro $^{1 *}$, Óscar J. Prado ${ }^{2}$ y Manuel García-Tasende ${ }^{3}$ \\ ${ }^{1}$ Instituto Español de Oceanografía (IEO), Centro Oceanográfico de Santander. Planta de Cultivo de \\ Algas "El Bocal", Barrio Corbanera s/n. (Monte), Apdo. 240, 39080 Santander. \\ ${ }^{2}$ AERIS Tecnologías Ambientales S.L. Edificio Eureka s/n., Campus de la Universitat Autònoma de \\ Barcelona (UAB), 08193 Bellaterra (Barcelona), España. \\ ${ }^{3}$ Xunta de Galicia, Consellería do Mar, Subdirección de Acuicultura. Edificios Administrativos San \\ Caetano, s/n., 15781 Santiago de Compostela, España \\ * Autor de correspondencia: peteiro@st.ieo.es
}

\section{Resumen}

Las macroalgas marinas contienen polisacáridos, lípidos y proteínas, entre otros componentes orgánicos, que se pueden utilizar para producir diferentes biocarburantes. Sin embargo, la producción de bioetanol es el que ha despertado actualmente un mayor interés por el alto contenido de polisacáridos (40-75\% de su peso seco) que presentan algunas grandes algas conocidas con el nombre de laminarias. Estas macroalgas marinas pueden utilizarse para la producción de bioetanol mediante un proceso de hidrólisis y fermentación de sus polisacáridos que ha sido mejorado recientemente para su aplicación industrial. Las laminarias ya se utilizan comercialmente para consumo humano, extracción de compuestos con múltiples aplicaciones industriales, pienso y forraje de animales y fertilizante. En este contexto, la acuicultura marina de laminarias en la costa atlántica de España puede constituir una fuente renovable, sostenible, limpia de biomasa para la obtención de bioetanol, además de otros productos con valor comercial. Su cultivo tendría importantes beneficios económicos pero también ambientales, al reciclar carbonos atmosféricos y nutrientes inorgánicos del medio marino. En la presente revisión se presenta una visión del proceso de producción de bietanol a partir de biomasa de laminarias y se discute el potencial de la maricultura de laminarias como fuente para producir bioetanol y otros bio-productos de valor en base a experiencias en la costa atlántica de España.

Palabras clave: acuicultura marina, aplicaciones, biocombustibles, macroalgas, kelp.

\begin{abstract}
Seaweeds contain polysaccharides, lipids and proteins, among other organic components, which can be used to produce different biofuels. However, bioethanol production has attracted more interest recently due to high content of polysaccharides (40-75\% of dry weight) in kelps. These seaweeds can be used for bioethanol production by the hydrolysis and fermentation of polysaccharides which it has been recently improved for industrial use. Kelps are already intended for direct human consumption, industrial extraction of valuable compounds, animal husbandry and agricultural (CThe Author(s) 2016. This article is published with open access by Sociedad Latinoamericana de Biotecnología Ambiental y Algal.
\end{abstract}


fertilizers. Consequently, kelp mariculture in the Spanish Atlantic coast may be a renewable, sustainable and environmentally friendly source for bioethanol production and many other valuable products. Besides its economic value, the mariculture would provide significant environmental benefits by recycling of atmospheric carbon and inorganic nutrients in coastal marine ecosystems. In this review an overview of the progress in converting kelp biomass into bioethanol is described. In addition, it is discussed the potential of kelp mariculture as source for bioethanol production and other valuable products based on experiences in the Atlantic coasts of Spain.

Key words: marine aquaculture, applications, biofuels, seaweeds, algas laminarias.

\section{Biocombustibles para el transporte}

Los biocarburantes son combustibles empleados específicamente para la automoción obtenidos a partir de biomasa, es decir, materias primas de origen biológico, que ofrecen una alternativa renovable frente a los carburantes derivados del petróleo (gasolina y diesel). Los biocombustibles líquidos, bioetanol y biodiesel, y el biogás son los principales biocarburantes empleados en la actualidad.

El etanol es el biocarburante más utilizado y desarrollado en la actualidad como un sustituto parcial o total de la gasolina. Se usa como biocarburante principalmente combinado al 5-15\% con gasolina en vehículos modernos y en concentraciones de hasta el $100 \%$ en vehículos con motores modificados (flexifuel). Además, la adición de derivados del bioetanol (ETBE) sirve para oxigenar la gasolina, lo que evita el uso de otros aditivos nocivos procedentes del petróleo. El bioetanol se obtiene por fermentación alcohólica de los azúcares contenidos en una biomasa vegetal realizada por diferentes microorganismos.

El biodiesel tiene propiedades muy similares al diesel obtenido del petróleo, por lo que puede utilizarse en forma pura en motores diesel sin modificar. Sin embargo, en los vehículos modernos se recomienda utilizar mezclas con gasóleo convencional hasta un $20 \%$ de biodiesel para evitar problemas en el rendimiento y mantenimiento de los vehículos. El biodiesel se puede producir a partir de gran variedad de aceites vegetales o grasas animales, aunque las principales fuentes son de origen vegetal. Existen varios caminos para la producción de biodiesel, sin embargo, el más comúnmente empleado consiste en la conversión química de los aceites grasos (triglicéridos) en biodiesel (éster), través de un proceso que se conoce como transesterificación. El biogas, mezcla constituida fundamentalmente por metano (biometano) y dióxido de carbono, puede ser utilizado en vehículos con motores modificados de gasolina $\mathrm{y}$ diesel que incorporan un mezclador de gases y un depósito independiente para ambos combustibles. Estos vehículos llamados bifuel utilizan distintas proporciones de biogas y carburante en el mismo motor. También existen vehículos pesados, como autobuses y camiones, que están diseñados para funcionar sólo con gas, aunque su utilización es minoritaria, limitándose principalmente a vehículos de transportes público. El biogas se puede obtener a partir de la digestión o descomposición de los compuestos orgánicos de la biomasa.

El uso de estos biocombustibles tiene importantes beneficios ambientales, estratégicos y económicos. A diferencia de los carburantes de origen fósil, el dióxido de carbono producido en la

CThe Author(s) 2016. This article is published with open access by Sociedad Latinoamericana de Biotecnología Ambiental y Algal. 
combustión de los biocarburantes es captado por la biomasa vegetal durante la fotosíntesis. Su balance de carbono es, por tanto, positivo de manera que contribuyen a mitigar las emisiones de gases de efecto invernadero responsables del cambio climático. Los biocarburantes además evitan la descarga de sustancias contaminantes al medio ambiente como son el plomo, el azufre $\mathrm{y}$ otros compuestos tóxicos derivados del petróleo. Por otra parte, la biomasa como fuente renovable $\mathrm{y}$ autóctona de biocombustibles en nuestro país tiene la ventaja de reducir la fuerte dependencia por los carburantes fósiles y el impacto de crisis relacionadas con el suministro y precio del petróleo. Con el fin de fomentar el uso de los biocarburantes, la Comisión Europea y sus Estados Miembros han puesto en marcha medidas para que en 2020 supongan al menos un $10 \%$ del consumo total de los combustibles para el transporte (Directiva 2009/28/CE).

\section{Las algas como fuente de biocombustibles}

Los principales problemas asociados con la obtención convencional de biocombustibles son la falta de disponibilidad de recursos y los altos costes de las materias primas de origen agrícola empleadas, además de que su uso extensivo afecta a la disponibilidad de alimentos así como de agua dulce. Como fuente alternativa se puede producir diferentes biocombustibles (llamados de segunda generación) a partir de algas a través del uso de nuevas tecnologías donde se integra su producción a la de otros productos de valor comercial dentro de lo que se conoce como biorefinería. De esta forma se mejoran los beneficios económicos, y es ambientalmente más beneficioso al reducirse los residuos o desechos generados en el proceso de obtención de estos biocombustibles. Recientemente, el Parlamento Europeo ha respaldado propuestas para promover la producción de biocarburantes de segunda generación frente a los convencionales (Propuesta aprobada por el Parlamento Europeo en su sesión plenaria del 28 de abril de 2015).

Las algas son organismos fotosintéticos que utilizan la energía de la luz para transformar el dióxido de carbono, el agua y nutrientes inorgánicos en oxígeno y biomasa vegetal. Se pueden diferenciar entre algas unicelulares microscópicas (microalgas) que viven libres en los sistemas acuáticos y algas multicelulares de mayor tamaño (macroalgas) que crecen adheridas a sustratos estables principalmente en fondos marinos.

Hasta hace unos años, la mayoría de los estudios sobre la producción de biocombustibles a partir de algas estaban relacionados con la obtención de biodiesel a partir de microalgas debido su alto contenido de lípidos, hasta un $50-60 \%$ de su peso. Sin embargo, la producción comercial de biodiesel a gran escala tiene como principal limitación los elevados costes del cultivo y de la cosecha de la biomasa microalgal (Chisti 2007; Gouveia and Oliveira 2009; Griffiths and Harrison 2009). Recientemente las macroalgas han despertado también un gran interés como fuente de biomasa para la producción de biocombustibles (Gosch et al. 2012; Hughes et al. 2012; Kraan 2013; Langlois et al. 2012; Wei et al. 2013). Estas grandes algas marinas presentan importantes ventajas respecto a otras materias primas vegetales, como son su rápido crecimiento, además de que su empleo no compromete el suministro de alimentos básicos $\mathrm{u}$ otros productos derivados de las cosechas. Además, la producción de macroalgas marinas no ocupa tierras ni requiere aporte de agua dulce, y su maricultura es factible y

CThe Author(s) 2016. This article is published with open access by Sociedad Latinoamericana de Biotecnología Ambiental y Algal. 
rentable a gran escala. De hecho la maricultura comercial de macroalgas es de gran relevancia al producir unas 20 millones de toneladas (peso fresco), lo que representa el $51 \%$ de la producción mundial de la acuicultura (FAO 2014).

\subsection{Las algas laminarias}

Las diferentes macroalgas se clasifican principalmente en tres grandes grupos dependiendo del color de sus pigmentos: las algas pardas (Phaeophyceae), las algas rojas (Rhodophyceae), y las algas verdes (Chlorophyceae). Estos grupos macroalgales presentan una gran diversidad de morfologías y tamaños que incluyen desde formas filamentosas hasta arborescentes. Las algas pardas conocidas con el nombre de laminarias son las que presentan un mayor tamaño, con un talo o fronde que puede alcanzar varios metros de longitud.

La biomasa de las macroalgas marinas contiene polisacáridos (compuestos ricos en azúcares), lípidos y proteínas, entre otros componentes orgánicos, que se pueden utilizar para producir diferentes biocarburantes. Estos serían el bioetanol a partir de la fermentación de los polisacáridos (Kraan 2013; Nahak et al. 2010; Wei et al. 2013), el biodiesel derivado de los lípidos mediante un proceso de transesterificación (Aresta et al. 2005; Gosch et al. 2012; Maceiras et al. 2011), y el biogás producido por una digestión anaerobia de los compuestos orgánicos de la biomasa (Chynoweth et al. 2001; Hughes et al. 2012; Langlois et al. 2012).

La idea de utilizar las macroalgas como fuente de biocombustible fue concebida por Howard Wilcox a principios de los años 70, después de la primera gran crisis mundial del petróleo. En esos años se inició en Estados Unidos un programa de investigación para evaluar la viabilidad técnica y económica de la producción de biometano (biogás) a partir de macroalgas. Hasta hace una década, la mayoría de las investigaciones sobre la obtención de biocombustibles a partir de macroalgas se centraban en la conversión de la biomasa macroalgal en biogás.

Actualmente la producción de bioetanol es la que ha despertado un mayor interés debido al elevado contenido de polisacáridos que presentan las macroalgas marinas y muy particularmente las laminarias (representan el 40-75\% de su peso seco). Además, la biomasa residual de la generación del bioetanol puede ser aprovechada para producir biogás $u$ otros productos de valor comercial como fertilizantes, forraje para alimentación animal y diferentes compuestos de aplicación industrial (Kraan 2013; Wei et al. 2013). Hasta ahora debido al bajo contenido de lípidos ó aceites de las macroalgas (menos del 10\% de su peso seco) se ha prestado poca atención a la obtención de biodiesel. Aunque algunos estudios consideran que la gran biomasa de las macroalgas puede ser también una buena fuente para la producción de biodiesel con nuevos métodos de extracción de aceites grasos (Bastianonia et al. 2008; Gosch et al. 2012).

\subsection{Conversión de las laminarias en bioetanol}

La producción de bioetanol mediante la fermentación de los polisacáridos de laminarias ha sido mejorada recientemente para su aplicación industrial (Adams et al. 2009; Kim et al. 2011; Wargacki et al. 2012; Wei et al. 2013). El proceso consiste en la hidrólisis o rotura de sus polisacáridos mediante tratamientos enzimáticos y en la fermentación de los azúcares resultantes por diferentes microorganimos.

Los polisacáridos de estas grandes algas (alginato, manitol, laminarina, y

CThe Author(s) 2016. This article is published with open access by Sociedad Latinoamericana de Biotecnología Ambiental y Algal. 
celulosa) varían a lo largo del año con cada especie, pero en general el contenido está entre el 40 y el $75 \%$ de su biomasa en peso seco (Schiener et al. 2015) (Figura 1). Como otros vegetales, las laminarias presentan tanto polisacáridos de reserva (manitol y laminarina) como polisacáridos estructurales de la pared celular (alginato y celulosa). Sin embargo, a diferencia de las plantas, sus polisacáridos estructurales no contienen lignina, un componente muy resistente que dificulta la hidrólisis de sus polisacáridos. Los polisacáridos de reserva son fácilmente hidrolizables, pero los estructurales de la pared celular requieren previamente su transformación en azúcares sencillos (proceso conocido como sacarificación) para su fermentación. En la hidrólisis de los polisacáridos se aplican sobre todo tratamientos enzimáticos (Choi et al. 2009; Jang et al. 2012), mientras que en la fermentación se utilizan diferentes microorganimos como levaduras y bacterias (Adams et al. 2009; Horn 2009) (Figura 2).

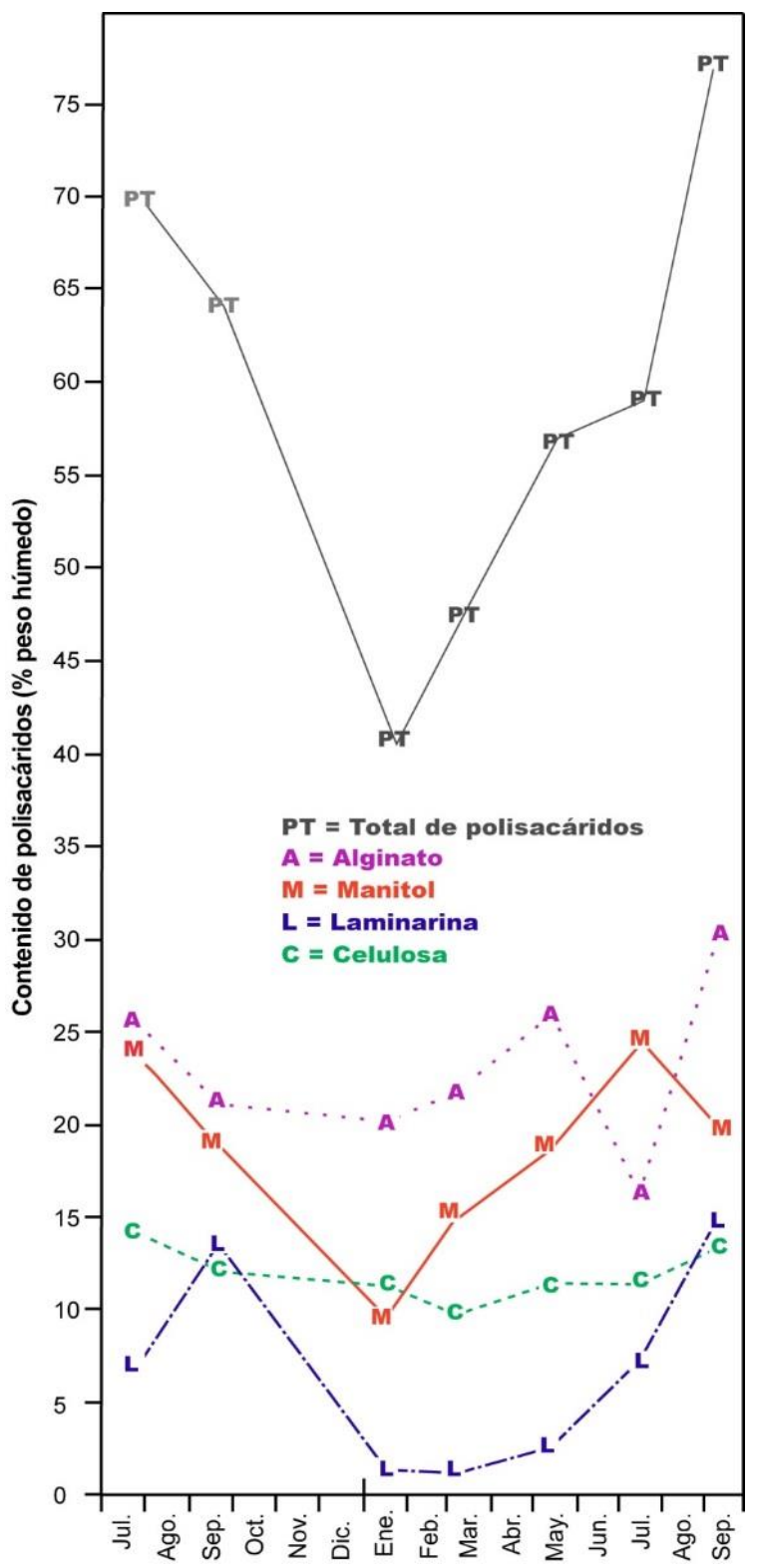

Figura 1. Contenido de polisacáridos de la laminaria Saccharina latissima a lo largo del año en las costas atlánticas. Datos obtenidos de Schiener et al. (2015).

CThe Author(s) 2016. This article is published with open access by Sociedad Latinoamericana de Biotecnología Ambiental y Algal. 


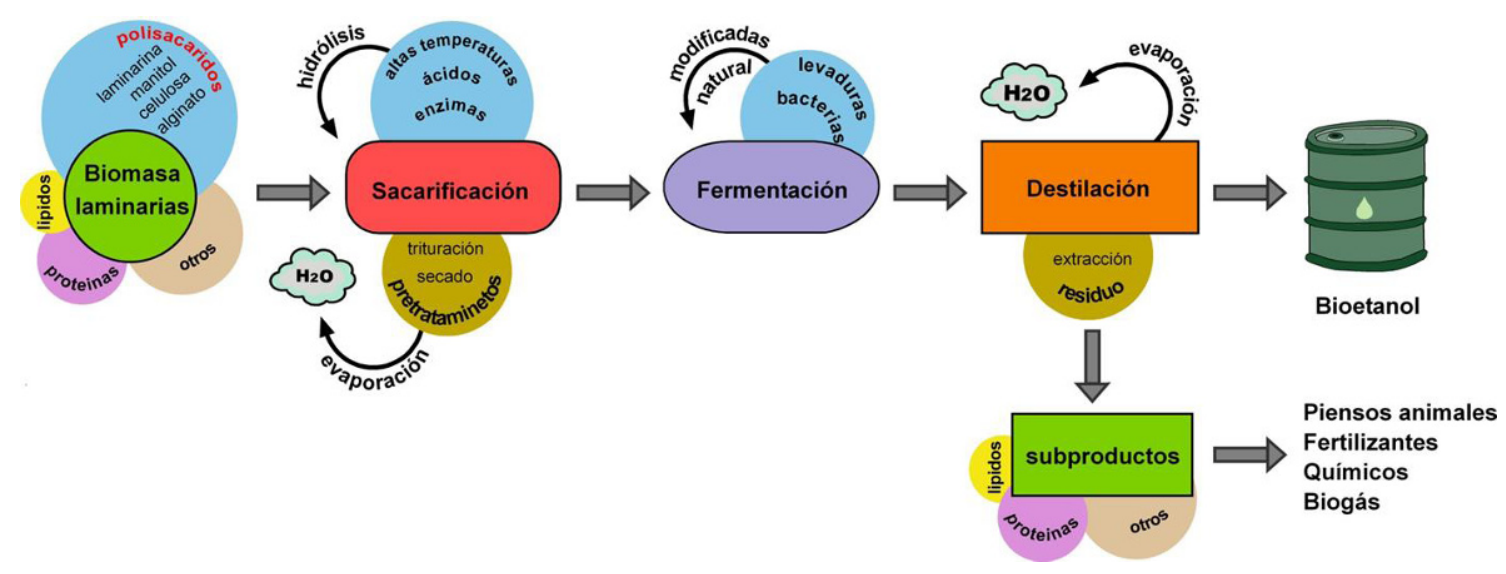

Figura 2. Conversión de los polisacáridos de laminarias en bioetanol a través de un proceso de hidrólisis y fermentación realizado por microorganismos.

Recientemente se han llevado a cabo investigaciones con el objeto de disponer de microorganismos más eficientes para la conversión directa de los polisacáridos macroalgales en bioetanol (Kim et al. 2011; Wargacki et al. 2012). Así, científicos del Bio Architecture Lab en Estados Unidos han conseguido modificar genéticamente la bacteria Escherichia coli para la hidrólisis y fermentación simultánea de los polisacáridos de las algas laminarias. De esta forma se ha logrado una conversión de 0,281 peso de etanol por peso seco de algas, lo que supone un rendimiento de etanol en un rango del $80 \%$ del valor teórico a partir del contenido de polisacáridos en la laminaria Saccharina japonica (Wargacki et al. 2012). Con estos rendimientos de conversión (partiendo de que un litro de etanol tiene un peso de $789 \mathrm{~g}$ ), la biomasa de laminarias necesaria para producir un litro de etanol es de $2,8 \mathrm{~kg}$ peso seco de algas. En la actualidad, se está ensayando el producir bioetanol y otros productos a partir de las algas laminarias en diferentes países de América y Europa.

\section{Acuicultura marina de laminarias en España}

Para el éxito de la producción de bioetanol a partir de algas laminarias es necesario un suministro sostenible de biomasa que permita su aplicación industrial como fuente de biocarburantes. Los recursos naturales de las laminarias son limitados, muy particularmente en las costas atlánticas de España, sin embargo su cultivo a gran escala es viable mediante técnicas sencillas y de bajo coste. Actualmente, la acuicultura de laminarias en Asia produce anualmente unas 8 millones de toneladas, mientras que en España se está empezado a cultivar de manera experimental o a pequeña escala (Peteiro and Freire 2009, 2011, 2012, 2013a; Peteiro et al. 2014).

Actualmente el Instituto Español de Oceanografía (IEO) dispone de la tecnología y conocimientos necesarios para el desarrollo de la maricultura de laminarias (Peteiro and Freire 2009, 2011, 2012, 2013a; Peteiro et al. 2014). Por ejemplo, la técnica para el cultivo en mar de la laminaria autóctona Saccharina lattisima, que se conoce con el nombre como "kombu de azúcar" ha sido ya desarrollada y optimizada a escala comercial en las costas de Galicia. En el cultivo de laminarias se

CThe Author(s) 2016. This article is published with open access by Sociedad Latinoamericana de Biotecnología Ambiental y Algal. 
reproducen las fases del ciclo de vida que caracteriza a estas algas, donde hay una alternancia entre una generación gametofitica formada por filamentos microscópicos y una generación esporofitica formada por una fronde macroscópica. Por este motivo la maricultura del "kombu de azúcar" se divide en dos fases muy diferenciadas: una primera de cultivo en laboratorio para la obtención de plántulas y una segunda de cultivo en mar donde estos jóvenes esporófitos crecen en el mar hasta que sus frondes alcanzan talla comercial.

La primera fase de laboratorio consiste en el cultivo en cámaras de simulación ambiental de gametófitos microscópicos que actúan como un "banco de semilla" (Figura 3). Estos gametófitos son sembrados sobre hilos y cultivados en tanques de embriogénesis con condiciones ambientales específicas producir plántulas. Estos hilos con plántulas recibe el nombre de "semilla" en la maricultura de laminarias (Figura 4). Para poder llevar a cabo el desarrollo y producción de "semilla" de laminarias a escala pre-industrial, el Instituto Español de Oceanografía (IEO) cuenta con un banco de germoplasma de especies de laminarias (colecciones de diferentes cepas en su fase gametofitica) que han sido seleccionadas desde los años noventa con diferentes criterios, entre otros, un rápido crecimiento de los esporófitos y resistencia de estos a altas temperaturas. Este banco es único y posee un gran valor, ya que puede proporcionar plántulas no solo para el cultivo comercial, sino también para la repoblación de zonas costeras que han sufrido alteraciones de origen natural y antrópico (García Tasende and Peteiro 2015; Peteiro and García-Tasende 2015).

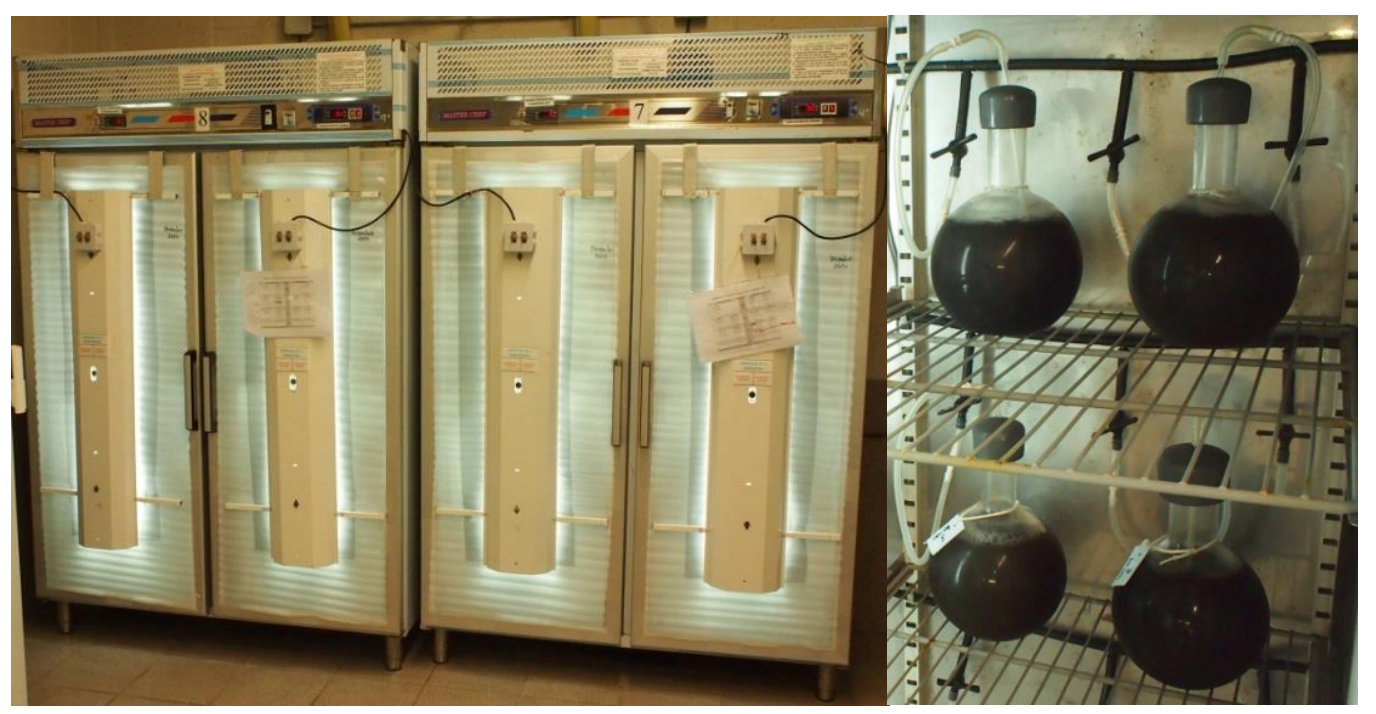

Figura 3. Cultivo en laboratorio de gametófitos de laminarias en botellones dentro de cámaras de simulación ambiental. Esta fase microscópica del ciclo de vida de laminarias actúa como un banco de germoplasma o de "semilla" con el que se puede obtener plántulas. 


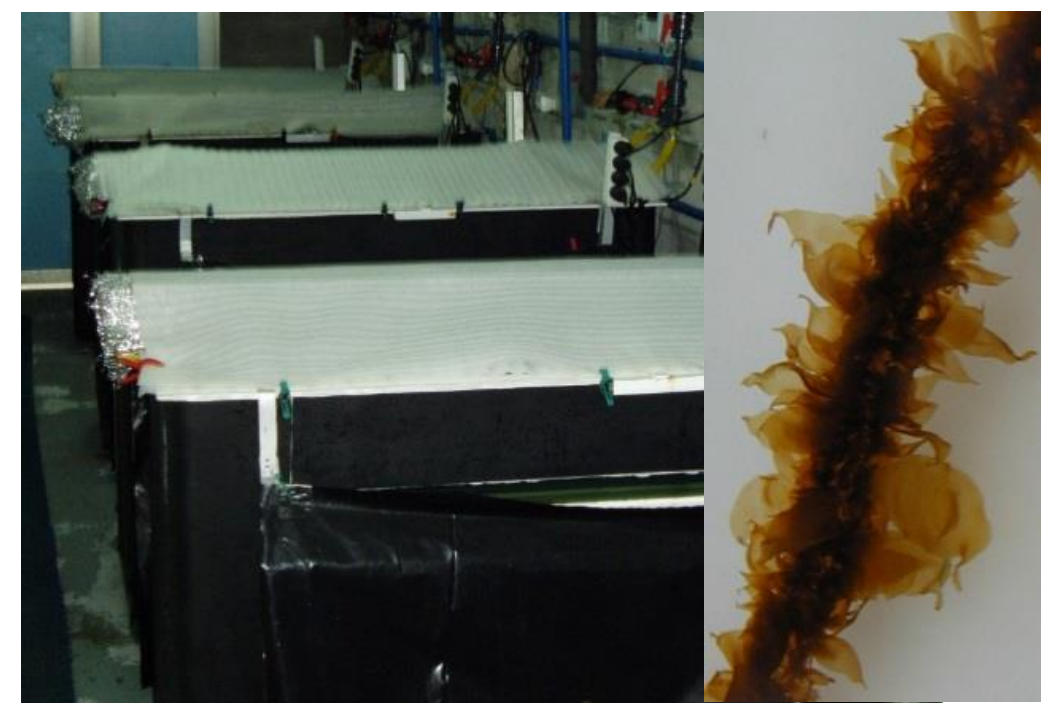

Figura 4. Para la obtención de plántulas de laminarias sus gametófitos se siembran sobre hilos que se cultivan en tanques de embriogénesis bajo condiciones ambientales específicas. Los hilos con plántulas son insertados sobre cabos para su cultivo en mar.

En la fase de cultivo en mar el hilo con plántulas de varios milímetros de longitud es implantado sobre cabos o cuerdas que se disponen en vertical $u$ horizontal dentro un parque de cultivo flotante (Figura 5). Los jóvenes esporófitos de varios milímetros de longitud crecen en el mar sobre cabos de cultivo hasta que sus frondes presentan una talla comercial de más de metro y medio. La biomasa obtenida en la maricultura del "kombu de azúcar" en Galicia (Noroeste de España) alcanza unos valores de hasta $16 \mathrm{~kg}$ peso fresco por metro lineal de cabo de cultivo después de unos 5 meses de cultivo en mar, aproximadamente unas 40 toneladas peso fresco (equivalente 4.7 toneladas peso seco) en una parque de cultivo de una hectárea (unos 2.500 metros de cabos sembrados) (Figura 6).
Sin embargo, se considera que esta producción por hectárea puede ser incrementada notablemente hasta duplicar estos valores con mayores densidades de cultivo (hasta el máximo de 4000 metros de cabos que permite la legislación vigente). De hecho, en otros países europeos a partir de valores de 4 a $10 \mathrm{~kg}$ peso fresco por metro lineal de cultivo de $S$. lattisima se han estimado producciones por hectárea de 120 y 220 toneladas peso fresco, respectivamente (Buck and Buchholz 2004; Sanderson et al. 2012) (Tabla 1).

CThe Author(s) 2016. This article is published with open access by Sociedad Latinoamericana de Biotecnología Ambiental y Algal. 


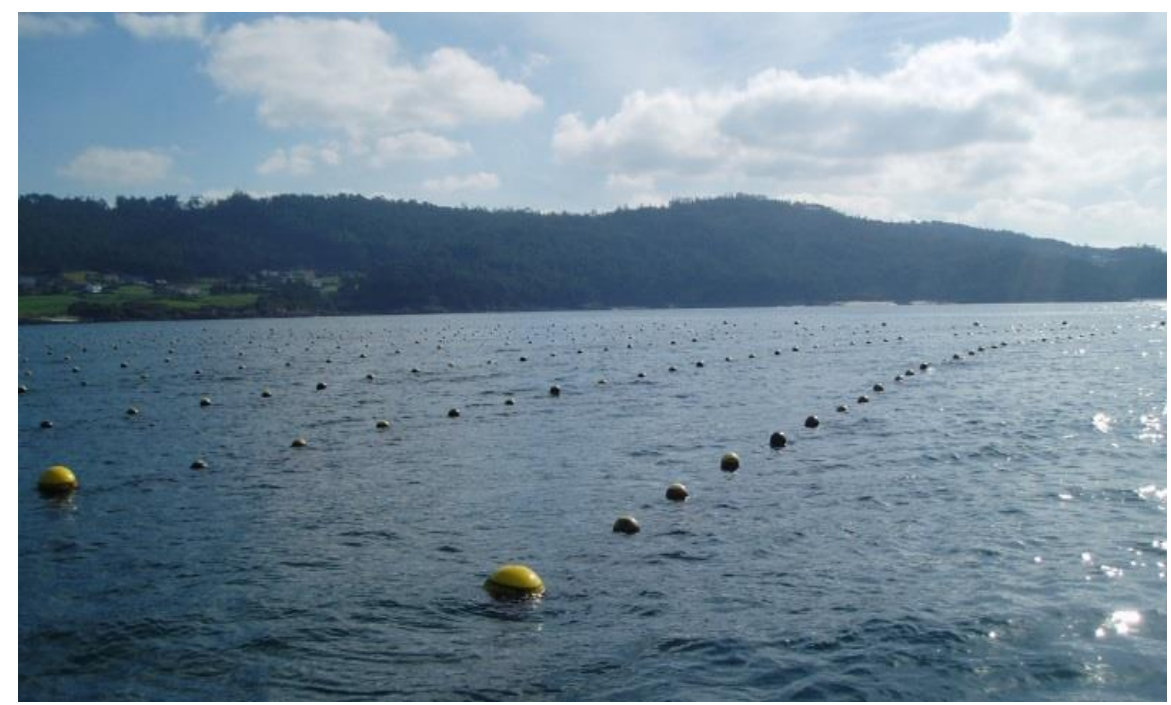

Figura 5. Aspecto de un parque de cultivo con algas laminarias en las rías gallegas. Los hilos con plántulas se plantan sobre cabos para su cultivo en mar, donde crecen hasta alcanzar una talla adulta

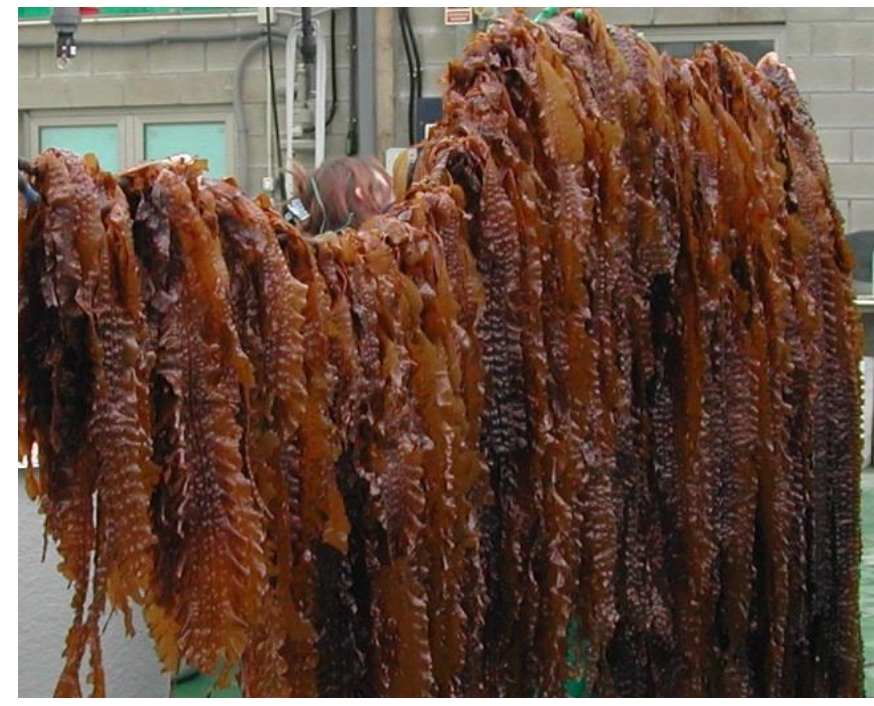

Figura 6. Cosecha de una laminaria después de varios meses de cultivo en el mar.

La producción alcanza unos valores de hasta $16 \mathrm{~kg}$ (en peso fresco) por metro lineal de cabo.

CThe Author(s) 2016. This article is published with open access by Sociedad Latinoamericana de Biotecnología Ambiental y Algal. 


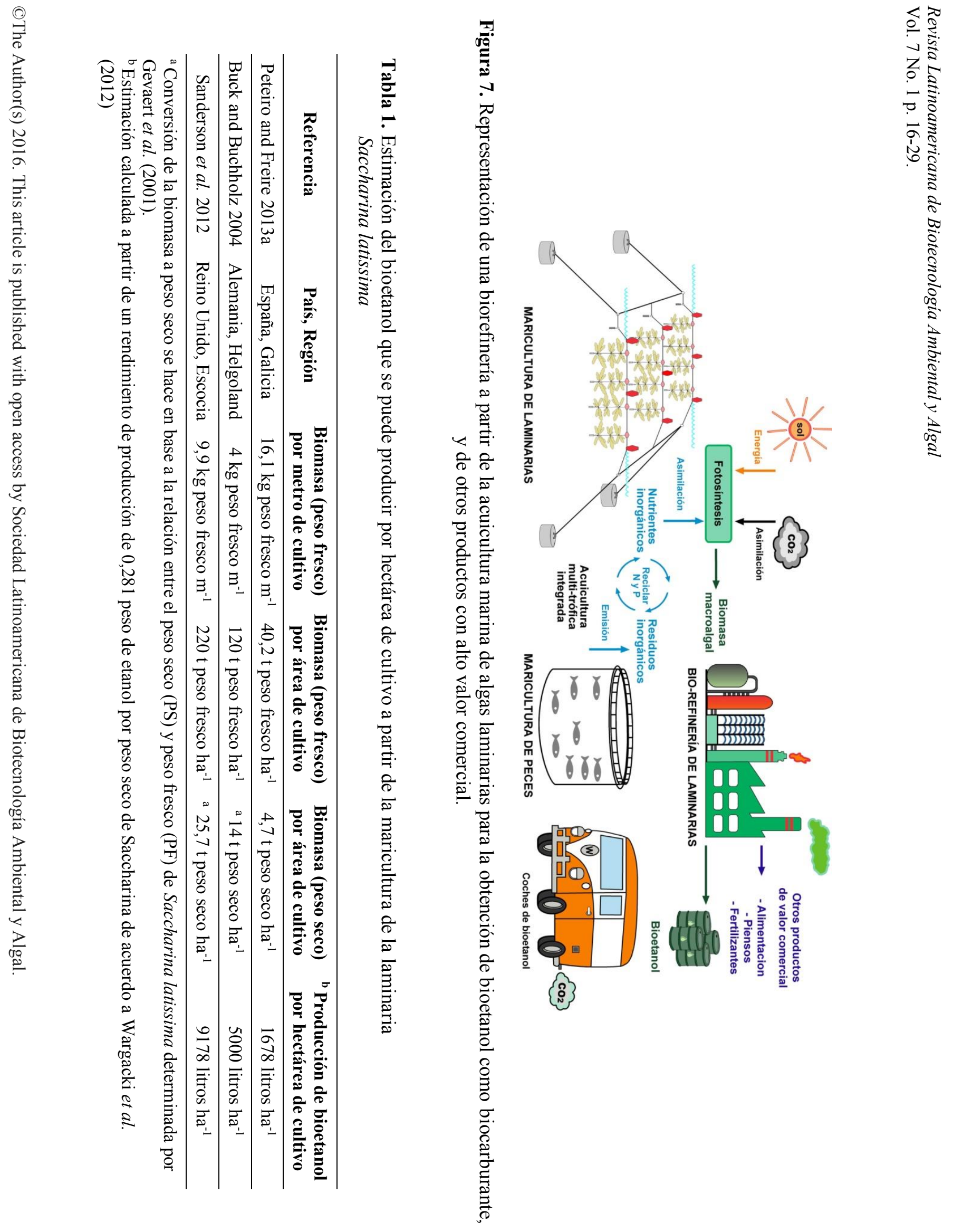


El cultivo de laminarias tendría importantes beneficios ambientales ya que las macroalgas para su crecimiento utilizan dióxido de carbono, nitrógeno y fósforo mediante la fotosíntesis, de modo que contribuyen a reducir el carbono atmosférico y los residuos inorgánicos del medio marino. Particularmente, el uso de los cultivos de macroalgas es de gran interés para el desarrollo de una acuicultura sostenible al absorber parte de los residuos inorgánicos que produce el cultivo de peces y moluscos. Esta asociación de organismos con diferentes niveles tróficos o nutricionales constituye un sistema de policultivo integrado, conocido como acuicultura multitrófica integrada (Buschmann et al. 2013). Por otra parte, las laminarias son actualmente utilizadas comercialmente en alimentación humana y como fertilizante y forraje para la acuicultura de herbívoros como el erizo de mar y la oreja de mar (García Tasende and Peteiro 2015; García Tasende and Rodríguez González 2003; Peteiro and García-Tasende 2015). Sus múltiples usos y potenciales aplicaciones se espera que se integren en bio-refinerías desarrolladas principalmente a partir de su cultivo en el mar. El concepto de biorefinería de laminarias es análogo a la de una refinería de petróleo que produce combustibles y múltiples productos a partir del petróleo. Así, por ejemplo, los residuos que se producen durante el procesado de las laminarias para consumo humano (hasta un $40 \%$ de su biomasa, Peteiro and Freire 2013b) se emplearían para producir biocarburantes o como fertilizante, forraje u otros usos. De la misma forma pueden ser utilizados para otras aplicaciones los subproductos que se obtienen en el proceso de producción de biocarburantes con estas macroalgas (Figura 7).

\section{Conclusiones}

Las algas laminarias tienen un alto contenido de polisacáridos (entre el 40 y $75 \%$ de su peso seco (Schiener et al. 2015) (Figura 1), que pueden utilizarse para la producción de bioetanol mediante un proceso de fermentación con microorganismos que ha sido mejorado recientemente para su aplicación industrial (Wargacki et al. 2012) (Figura 2).

El éxito de estas grandes algas como fuente de biocombustibles sólo es posible con el desarrollo de su cultivo a gran escala, que garantice un suministro de biomasa. En base a los rendimientos actuales de conversión de los polisacáridos de la biomasa de laminarias en bioetanol (Wargacki et al. 2012) se estima una producción de 1.678 litros de bioetanol por hectárea a partir de los valores de cosecha obtenida en el cultivo de $S$. lattisima en España (Peteiro and Freire 2013a). Aunque se considera que esta producción puede ser duplicada con mayores densidades de cultivo de acuerdo a estimaciones de producción por hectárea que se han hecho en otros países europeos (Buck and Buchholz 2004; Sanderson et al. 2012) (Tabla 1). Como actualmente en Galicia se está empezando a cultivar $S$. lattisima para consumo humano, los deshechos de biomasa que se generan en su procesado pueden ser también utilizados para la obtención de bioetanol (Peteiro and Freire 2013b), aportando un valor añadido a su cultivo. Además, en el proceso de producción de bioetanol se generan residuos de biomasa macroalgal que puede ser aprovechada para producir otros subproductos con alto valor comercial como fertilizantes $y$ forraje para 
alimentación animal, entre otros (Kraan 2013; Wei et al. 2013).

Como conclusión, la acuicultura marina de laminarias en la costa atlántica de España puede constituir en un futuro próximo una fuente limpia y renovable de biomasa para la obtención de biocarburante, además de otros subproductos con valor comercial. Su desarrollo, tendría importantes beneficios ambientales además de económicos (Figura 7).

Open Access: This article is distributed under the terms of the Creative Commons Attribution License (CC-BY 4.0) which permits any use, distribution, and reproduction in any medium, provided the original author(s) and the source are credited

\section{Referencias}

Adams, J.M., Gallagher, J.A., Donnison, I.S. 2009. Fermentation study on Saccharina latissima for bioethanol production considering variable pretreatments. J Appl Phycol 21: 569574.

Aresta, M., Dibenedetto, A., Carone, M., Colonna, T., Fragale, C. 2005. Production of biodiesel from macroalgae by supercritical $\mathrm{CO}_{2}$ extraction and thermochemical liquefaction Environ Chem Lett 3(3): 136-139.

Bastianonia, S., Coppolaa, F., Tiezzia, E., Colacevichb, A., Borghinib, F., Focardib, S. 2008. Biofuel potential production from the Orbetello lagoon macroalgae: A comparison with sunflower feedstock. Biomass Bioenerg 32: 619-628.

Buck, B.H., Buchholz, C.M. 2004. The offshore-ring: a new system design for the open ocean aquaculture of macroalgae. J Appl Phycol 16: 355368.

Buschmann, A.H., Stead, R.A., Hernández-González, M.C., Pereda, S.V. 2013. Un análisis crítico sobre el uso de macroalgas como base para una acuicultura sustentable. Rev Chil Hist Nat 86: 251-264.

Chisti, Y. 2007. Biodiesel from microalgae. Biotechnol Adv 25: 294306.

Choi, D., Sim, H.S., Piao, Y.L., Ying, W., Cho, H. 2009. Sugar production from raw seaweed using the enzyme method. J Ind Eng Chem 15: 12-15.

Chynoweth, D.P., Owens, J.M., Legrand, R. 2001. Renewable methane from anaerobic digestion of biomass Renew Energy 22(1-3): 1-8.

FAO 2014. El estado mundial de la pesca y la acuicultura. Food and Agriculture Organization of the United Nations (FAO), Rome. 253 p.

García Tasende, M., Peteiro, C. 2015. Explotación de las macroalgas marinas: Galicia como caso de estudio hacia una gestión sostenible de los recursos. Revista Ambienta ${ }^{\circ}$ 111 / Junio: 116-132.

García Tasende, M., Rodríguez González, L.M. 2003. Economic seaweeds of Galicia (NW Spain). Thalassas 19(1): 17-25.

Gevaert, F., Davoult, D., Creach, A., Kling, R., Janquin, M.A., Seuront, L., Lemoine, Y. 2001. Carbon and nitrogen content of Laminaria saccharina in the eastern English Channel: biometrics and seasonal variations. J Mar Biol Assoc UK 81: 727-734.

Gosch, B.J., Magnusson, M., Paul, N.A., de Nys, R. 2012. Total lipid and fatty

(C) The Author(s) 2016. This article is published with open access by Sociedad Latinoamericana de Biotecnología Ambiental y Algal. 
acid composition of seaweeds for the selection of species for oil-based biofuel and bioproducts. $G C B$ Bioenergy 4(6): 919-930.

Gouveia, L., Oliveira, A.C. 2009. Microalgae as a raw material for biofuels production. $J$ Ind Microbiol Biotechnol 36(2): 269-274.

Griffiths, M.J., Harrison, S.T.L. 2009. Lipid productivity as a key characteristic for choosing algal species for biodiesel production. $J$ Appl Phycol 21(5): 493-507.

Horn, S.J. 2009. Seaweeds Biofuels: Production of biogas and bioethanol from brown Macroalgae. VDM Verlag. 201 p.

Hughes, A.D., Kelly, M.S., Black, K.D., Stanley, M.S. 2012. Biogas from macroalgae: is it time to revisit the idea? Biotechnol Biofuels 5: 1-86.

Jang, S.S., Shirai, Y., Uchida, M., Wakisaka, M. 2012. Production of mono sugar from acid hydrolysis of seaweed. Afr $J$ Biotechnol 11(8): 1953-1963.

Kim, N.-J., Li, H., Jung, K., Chang, H.N., Lee, P.C. 2011. Ethanol production from marine algal hydrolysates using Escherichia coli KO11. Bioresour Technol 102(16): 7466-7469.

Kraan, S. 2013. Mass-cultivation of carbohydrate rich macroalgae, a possible solution for sustainable biofuel production. Mitig Adapt Strat Global Change 18(1): 27-46.

Langlois, J., Sassi, J.-F., Jard, G., Steyer, J.-P., Delgenes, J.-P., Hélias, A. 2012. Life cycle assessment of biomethane from offshore-cultivated seaweed. Biofuels, Bioproducts and Biorefining 6(4): 387-404.

Maceiras, R., Rodriguez, M., Cancela, A., Urrejola, S., Sanchez, A. 2011.
Macroalgae: raw material for biodiesel production. Appl Energy 88(10): 3318-3323.

Nahak, S., Nahak, G., Pradhan, I., Sahu, R.K. 2010. Bioethanol from marine algae: a solution to global warming problem. J Appl Environ Biol Sci 1(4): 74-80.

Peteiro, C., Freire, Ó. 2009. Effect of outplanting time on the commercial cultivation of the kelp Laminaria saccharina at the southern limit in the Atlantic coast, N.W. Spain. Chin J Oceanol Limnol 27(1): 54-60.

Peteiro, C., Freire, Ó. 2011. Effect of water motion on the cultivation of the commercial seaweed Undaria pinnatifida in a coastal bay of Galicia, Northwest Spain. Aquaculture 314(1-4): 269-276.

Peteiro, C., Freire, Ó. 2012. Outplanting time and methodologies related to mariculture of the edible kelp Undaria pinnatifida in the Atlantic coast of Spain. J Appl Phycol 24(6): 1361-1372.

Peteiro, C., Freire, Ó. 2013a. Biomass yield and morphological features of the seaweed Saccharina latissima cultivated at two different sites in a coastal bay in the Atlantic coast of Spain. J Appl Phycol 25(1): 205213.

Peteiro, C., Freire, Ó. 2013b. Epiphytism on blades of the edible kelps Undaria pinnatifida and Saccharina latissima farmed under different abiotic conditions. J World Aquacult Soc 44(5): 706-715.

Peteiro, C., García-Tasende, M. 2015. Uso y cultivo de laminarias, las grandes algas marinas. Investigación y Ciencia $\mathrm{n}^{\circ} 466$ - Julio: 8-9.

Peteiro, C., Sánchez, N., Dueñas-Liaño, C., Martínez, B. 2014. Open-sea

(C) The Author(s) 2016. This article is published with open access by Sociedad Latinoamericana de Biotecnología Ambiental y Algal. 
cultivation by transplanting young fronds of the kelp Saccharina latissima. J Appl Phycol 26(1): 519528.

Sanderson, J.C., Dring, M.J., Davidson, K., Kelly, M.S. 2012. Culture, yield and bioremediation potential of Palmaria palmata (Linnaeus) Weber \& Mohr and Saccharina latissima (Linnaeus) C.E.Lane, C.Mayes, Druehl \& G.W.Saunders adjacent to fish farm cages in north west Scotland. Aquaculture 354: 128-135.

Schiener, P., Black, K.D., Stanley, M.S., Green, D.H. 2015. The seasonal variation in the chemical composition of the kelp species Laminaria digitata, Laminaria hyperborea, Saccharina latissima and Alaria esculenta. J Appl Phycol 27(1): 363-373.

Wargacki, A.J., Leonard, E., Win, M.N., Regitsky, D.D., Santos, C.N.S., Kim, P.B., Cooper, S.R., Raisner, R.M., Herman, A., Sivitz, A.B., Lakshmanaswamy, A., Kashiyama, Y., Baker, D., Yoshikuni, Y. 2012. An engineered microbial platform for direct biofuel production from brown macroalgae. Science 335(308): 308313.

Wei, N., Quarterman, J., Jin, Y.S. 2013. Marine macroalgae: an untapped resource for producing fuels and chemicals. Trends Biotechnol 31(2): 70-77. 